\title{
ELECCIONES GENERALES EN DINAMARCA (10 DE ENERO DE 1984)
}

La decisión del Gobierno de centro-derecha, presidido por Poul Schluter, de convocar elecciones anticipadas en Dinamarca ha estado motivada, principalmente, por la precariedad del poder que ostentaban y que había ocasionado el rechazo, en el Parlamento danés, del Presupuesto presentado por el Gobierno para el presente año, al votar en contra parte de las minorías en las que la coalición gubernamental venía apoyándose para llevar a cabo su política.

En Dinamarca, durante los últimos tiempos, se ha manifestado uno de los problemas clásicos del pluripartidismo, como es la manifestación de una cierta inestabilidad de los gobiernos. Indudablemente, en un sistema pluripartidista, la opinión pública se encuentra más estrictamente identificada que en un sistema bipartidista, aunque este último puede mejorar la estabilidad política. Sin duda, la coalición de centro-derecha que ha gobernado Dinamarea desde 1981, fecha de las últimas elecciones, se ha visto sometida a los avatares y la inestabilidad propias de la opción pluripartidista. Estas nuevas elecciones anticipadas no han consolidado a la coalición en el poder, aunque le van a permitir seguir ostentándolo. Con todo, tẹndrán enfrente a una poderosa oposición de izquierdas, al frente de la cual se encuentra el Partido Socialista, que, con sus 57 escaños, ha sido el partido más votado eri estas elecciones, aunque haya perdido dos escaños con respecto a las elecciones de 1981.

Las consecuencias y conclusiones más importantes de estas elecciones danesas son, por un lado, que, aunque se ha mantenido, en general, el voto conservador, éste no ha eclipsado la poderosa fuerza del voto socialista y socialdemócrata, dejando el poder a las mismas fuerzas políticas, la coalición conservadora, pero sin que ésta haya conseguido la consolidación que buscaba y que la hubiera permitido salir de la encrucijada de los partidos menores, en los que ha necesitado y seguirá necesitando apoyarse para sacar adelante su programa y, de forma muy especial, el Presupuesto y el resto de las medidas económicas, que, a la postre, fueron las que provocaron la crisis y estas nuevas elecciones.

El nuevo Gobierno, al igual que el anterior, está formado por el Partido Liberal, Centro Demócrata, Popular Cristiano y Conservador, mientras que la oposición de izquierdas agrupa al Partido Socialista Popular, Socialista de Izquierdas y Socialdemócratas.

De otro lado, el gran perdedor ha sido el Partido del Progreso, que ha visto cómo se reducían sus 16 escaños a 6 en estas elecciones, lo que le impedirá, además, realizar una cierta función de arbitraje, a nivel parlamentario, que sí llevó a cabo en la etapa anterior. 
A continuación insertamos los resultados de estas elecciones y, comparativamente, los de las anteriores celebradas en 1981:

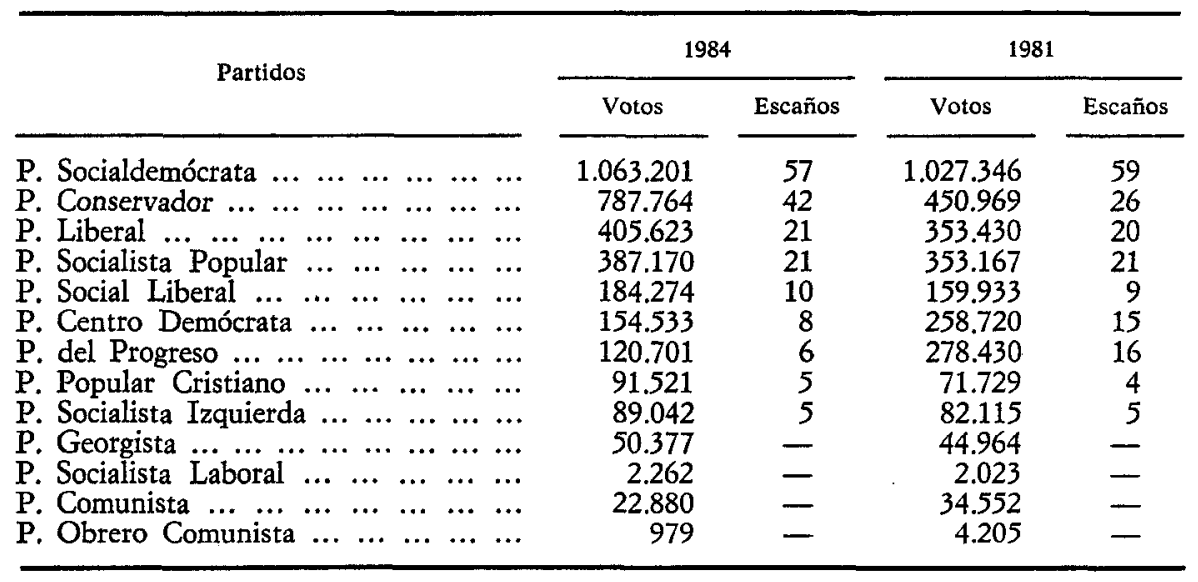

FUENTE: Embajada de Dinamarca en Madrid.

Yolanda Gómez SánChez 